\title{
Identification and Antimicrobial Susceptibility of Yersinia enterocolitica Found in Chitterlings, Raw Milk and Swine Fecal Samples
}

\author{
F. N. Drake, S. Davis, J. Khatiwada, L. Williams \\ North Carolina A \& T State University, North Carolina Research Campus, Kannapolis, NC, USA \\ Email:1lw@ncat.edu
}

How to cite this paper: Drake, F.N., Davis, S., Khatiwada, J. and Williams, L. (2018) Identification and Antimicrobial Susceptibility of Yersinia enterocolitica Found in Chitterlings, Raw Milk and Swine Fecal Samples. Advances in Microbiology, 8, 804-820.

https://doi.org/10.4236/aim.2018.810053

Received: August 24, 2018

Accepted: October 28, 2018

Published: October 31, 2018

Copyright $\odot 2018$ by authors and Scientific Research Publishing Inc. This work is licensed under the Creative Commons Attribution International License (CC BY 4.0).

http://creativecommons.org/licenses/by/4.0/

cc) (i) Open Access

\begin{abstract}
Foodborne illness is an escalating concern upon public health. The prevalence of Yersinia enterocolitica was assessed in chitterlings, raw milk and swine fecal from North Carolina. Uncleaned thirty chitterling samples procured from a local grocery store, forty-five swine fecal samples, and forty unpasteurized cow milk samples supplied by the University farm were evaluated for the presence of $Y$. enterocolitica. Isolates identified as presumptive positive were characterized as colonies with a pink or deep-red center on MacConkey and CIN agar, and verified further through polymerase chain reaction (PCR) for the presence of 16S rRNA gene for the Yersinia genera. Results showed that $4.4 \%$ swine fecal samples, $7.5 \%$ milk samples and $11.3 \%$ chitterling samples were presumptive positive for $Y$. enterocolitica by the direct plating method on selective agars. Of the thirty-chitterling samples examined by PCR for the 16S rRNA gene, 26\% samples contained the identification gene for the bacteria of interest. After conducting virulence tests, the fecal samples were revealed as non-pathogenic. Only one of the milk samples were considered pathogenic and consisted of the following virulent genes: Yersinia heat-stable toxin ( $y s t)$, invasion (inv), attachment invasion locus (ai), virulence regulon transcriptional activator $(\operatorname{vir} \mathrm{F})$, Yersinia adehesin A ( $\operatorname{yadA})$, and the O:3 antigen gene $(r f b C)$. Seven out of the eight $(87.5 \%)$ chitterling samples were shown to be pathogenic. Disc diffusion was conducted to determine the antimicrobial susceptibility of the isolates. Over half (55.5\%) of the antimicrobial agents were found effective, with isolates being completely susceptible to ciprofloxacin, kanamycin, trimethoprim, cefotaxime, and gentamycin. Ampicillin was determined to be least effective, where $84.6 \%$ of the samples presented resistance to the drug. Random amplified polymorphic DNA (RAPD) analysis and ERIC-PCR techniques were used to evaluate genetic similarity among the Yersinia isolates. There was approximately $85 \%$ similarity between
\end{abstract}


two chitterlings and a fecal isolate during RAPD testing. With ERIC-PCR the largest similarity among all samples was at $95 \%$, which was found between isolates from a chitterling and milk sample. Chitterling samples showed the highest prevalence of $Y$. enterocolitica compared to the other samples. Cross contamination at the farm level could be the root cause of this pathogen being prevalent in farm animal and food sources, which does pose a risk to public human health when food is improperly prepared.

\section{Keywords}

Yersinia enterocolitica, Polymerase Chain Reaction, Antimicrobial

\section{Introduction}

Foodborne illness is a growing public health concern. The main source of acquiring Yersinia enterocolitica infection is through the consumption of the contaminated food or beverage. The CDC approximates that each year $Y$. enterocolitica is the cause of 117,000 illnesses, 640 hospitalizations, and 35 deaths [1]. Yersinia enterocolitica is a type of bacteria that primarily resides in the intestines of pigs and causes Yersiniosis diseases to human being after consuming the contaminated foods. The symptoms are noticeable $4-7$ days after infection. The main symptoms of this disease are watery diarrhea, abdominal pain, headache, vomiting, and fever. Pseudo-appendicitis is also a symptom of infection because the abdominal pain is sometimes mistaken for appendicitis. Immune-compromised individuals may experience arthritis, meningitis, and inflammation of the skin [2]. Symptoms of Yersiniosis vary in age of infected persons, but are more common in young children, typically, young children with yersiniosis will produce bloody diarrhea [1]. Yersiniosis at the enteric site typically goes away on its own in healthy people. In recent years, approximately $17 \%$ of patients in Germany were hospitalized for 4 days, with a few deaths accounted for individuals older than 60 years of age [3].

Pigs have been identified as a major reservoir for $Y$. enterocolitica. Strains of the biotype 4 and serotype O:3 have been isolated from humans infected in European countries. The amount of $Y$. enterocolitica was found to be greater in the tonsils and tongues of pigs when compared to the amounts that were measured from the cecal and fecal materials of pigs. Additionally, biotypes 2 and 3 and serotypes O:5.27, O:8, and O:9 have been detected from slaughter pigs. The reservoir of these strains has not been clearly identified; however, it was suspected that contamination occurs during the processing of the pigs after slaughtered [4]. Virulent $Y$. enterocolita strains have been detected in raw pork samples including loin, fillet, chops, ham, minced meat, and ready to eat pork products [4].

Rahman et al. [4] reported that dairy products, vegetables, other types of raw meats, and sewage/drinking water have also revealed the presence of $Y$. enterocolitica. It is also reported that $Y$. enterocolitica could replicate in deli meats, as 
well as unpasteurized milk products. The bacteria amplified in foods that were stored at typical refrigerator temperatures [5]. Fruits and vegetables can become contaminated when the water used to irrigate the fresh produce has been contaminated with human or animal fecal matter. If cooking utensils or kitchen countertops have not been properly cleaned they pose the risk of transmitting $Y$. enterocolitica, which leads to foodborne illness [5].

Foodborne Diseases Active Surveillance Network (FoodNet) reported that $Y$. enterocolitica infections were greatest in young black children in the United States from 1996-2009 [6]. A peak of incidents was observed during winter months, which are the holiday seasons. An association was made between chitterlings and $Y$. enterocolitica infections in young black children. Chitterlings, which are the intestines of pigs is an African-American cultural dish that is often prepared in the home and served during the holidays. This study suggested that chitterlings were the source of infection [7]. While pigs are a known reservoir for $Y$. enterocolitica, other animals have also been known to be a host to this bacterium. Fresh produce has also been known to be a source of $Y$. enterocolitica. There was an outbreak in Norway in 2011 with 21 confirmed cases of infection by $Y$. enterocolitica O:9. None of the individuals died, however; 17 of them became sick with symptoms of yersiniosis. $Y$. enterocolitica was isolated from 11 pre-packaged salad products but none of them contained the serotype O:9 that was detected in the sick individuals [8]. Contamination of fruits and vegetables can occur at any level of the production process. $Y$. enterocolitica has been found present in fruits [9]. Enteric pathogens such as $Y$. enterocolitica have been shown to multiply on the surface of cut melons [10].

Based on biochemical and serological tests, $Y$. enterocolitica is divided into six biotypes and distinct serotypes. The biotypes $1 \mathrm{~B}, 2,3,4$ and 5 are grouped as pathogenic, whereas the biotype $1 \mathrm{~A}$ strain is non-pathogenic to humans and animals [11], where as strains of bio-serotypes 4/O:3 and 2/O:9 are commonly associated with human yersiniosis. Varieties of animals have been studied for isolation of $Y$. enterocolitica. There was a difference between the biochemical and serological traits of strains taken from animals when compared to strains taken from humans. Strains that cause disease in humans have often been isolated from the tonsil and fecal samples of butchered pigs. Pigs were reported as the major reservoir for human infection of $Y$. enterocolitica. Sows could pass pathogenic Yersinia to their weaning piglets. In Great Britain, pigs and sheep were shown to be a source for $Y$. enterocolitica $4 / \mathrm{O}: 3$ and 3/O:9, leading to infection in humans. The bio-serotype 4/O:3 has been sampled from dogs and cats. Therefore, pets within the home are suggested to be a risk for infection to humans [12]. Farm animals (pigs, cattle, sheep, goats, and chicken), mammals (rodents, hares, foxes), pet animals (dogs, cats), environment (water, sewage) and foods (meat, dairy goods, seafood, veggies) were all identified as natural reservoirs of $Y$. enterocolitica [13] (Table 1).

In current situation, volume of the research works related to Yersinia enterocolitica has been carried out in European and Asian countries, not in the US, 
Table 1. Primers used to distinguish the virulence genes in $Y$. enterocolitica.

\begin{tabular}{|c|c|c|c|}
\hline Gene & Primer Name & Sequence $\left(5^{\prime} \rightarrow 3^{\prime}\right)$ & Amplicon Length (BP) \\
\hline \multirow{2}{*}{ yst } & ystF & GTT AAT GCT GTC TTC ATT TGG AGC & \multirow{2}{*}{145} \\
\hline & ystR & GAC ATC CCA ATC ACT ACT GAC TTC & \\
\hline \multirow{2}{*}{ inv } & invF & CTG TGG GGA GAG TGG GGA AGT TTG G & \multirow{2}{*}{570} \\
\hline & invR & GAA CTG CTT GAA TCC CTG AAA ACC G & \\
\hline \multirow{2}{*}{ ail } & ailF & ACT CGA TGA TAA CTG GGG AG & \multirow{2}{*}{170} \\
\hline & ailR & CCC CCA GTA ATC CAT AAA GG & \\
\hline \multirow{2}{*}{ virF } & $\operatorname{virF-F}$ & TCA TGG CAG AAC AGC AGT CAG & \multirow{2}{*}{590} \\
\hline & virF-R & ACT CAT CTT ACC ATT AAG AAG & \\
\hline \multirow{2}{*}{$y s t B$} & ystB-F & AAC TTT TTG GAC ACC GCA CAG & \multirow{2}{*}{208} \\
\hline & ystB-R & GTC TGA GTA TCG CAC GCT & \\
\hline \multirow{2}{*}{$\operatorname{yad} A$} & yadA-F & CTT CAG ATA CTG GTG TCG CTG T & 849 \\
\hline & yadA-R & ATG CCT GAC TAG AGC GAT ATC C & 759 \\
\hline \multirow{2}{*}{$r f b C$} & $\mathrm{rfbC}-\mathrm{F}$ & CGC ATC TGG GAC ACT AAT TCG & \multirow{2}{*}{405} \\
\hline & $\mathrm{rfbC}-\mathrm{R}$ & CCA CGA ATT CCA TCA AAA CCA CC & \\
\hline \multirow{2}{*}{ ystC } & ystC-F & GAG GCT GAG TGC GG & \multirow{2}{*}{83} \\
\hline & ystC-R & GCA GGA TTG CAA CA & \\
\hline
\end{tabular}

thus the objectives of this study were to identify, evaluate and access the antimicrobial activities of Yersinia enterocolitica isolates present in Chitterlings, Raw milk and Swine fecal samples.

\section{Materials and Methods}

\subsection{Samples Collection}

A total of 115 samples were collected for this study, of which 45 swine fecal and 40 cattle raw milk were aseptically collected from the North Carolina A\&T State University farm in Greensboro, North Carolina. Unclean Chitterling samples (30) were purchased from local grocery store. Generally, samples were collected during the cold months of (November and December) the year of 2016. The samples were transported in the cooler containing ice, and sampled immediately upon arrival to the laboratory.

\subsection{Isolation of $Y$, enterocolitica}

With minor modifications, isolation and recognition of presumptive positive strains of Yersinia enterocolitica were performed according to the Bacteriological Analytical Manual [14]. Raw Milk: One milliliter of each sample was added to $9 \mathrm{~mL}$ of irgasan-ticarcillin-potassium chlorate (ITC) broth and were selectively enriched for 7 days at $25^{\circ} \mathrm{C}$. Fecal: Five milliliters of ITC broth were placed in each swab container and enriched for 7 days at $25^{\circ} \mathrm{C}$. Chitterlings: Twenty-five grams of each sample was compositely weighed and placed in a stomacher bag with $225 \mathrm{~mL}$ of ITC broth. The samples were homogenized for 30 seconds and then directly plated. The enrichment phase was not applied to the chitterlings due to anticipation of high levels of $Y$. enterocolitica. At the end of the enrichment phase for fecal and milk, and after homogenization of the chit- 
terling samples, $100 \mu \mathrm{L}$ of each sample was transferred to $900 \mu \mathrm{L}$ of $0.5 \% \mathrm{NaCl}$ in efforts to suppress the growth of unwanted microorganisms. One loopful was then streaked onto cefsulodin-irgasan-novobiocin (CIN) agar, as well as MacConkey agar (MCA). ATCC 9610 was used as a positive control. The agar plates were incubated at $30^{\circ} \mathrm{C}$ for 48 hour. Either presenting a pale-pink or a deep-red "bull's eye" center formation in the agar identified as presumptive positive sample. The colonies were stored in tryptic soy agar slants for future use.

\subsection{Identification of $16 \mathrm{~S}$ rRNA and Virulence Genes by Polymerase Chain Reaction}

The DNA was extracted by way of the boiling method. The PCR procedure used to identify the 16S rRNA gene was followed according to Neubauer et al. (2000). The primers chosen and amplicon values are shown in Table 2. The PCR conditions for distinguishing virulence genes were obtained from the following: for yst, Gomez-Durate et al. [15]; for inv, Rasmussen et al. [16]; for ail, Nakajima et al. [17]; for virF, Amin Askr et al. [18]; for ystB, Garzetti et al. [19]; for yadA, Wang et al. [20]; for $r f b C$, Weynants et al. [21]; and for $y s t C$, Bhagat and Virdi [22].

Briefly, a master mix containing $24.25 \mu \mathrm{L}$ of autoclaved water, $10 \mu \mathrm{L}$ of $5 \mathrm{X}$ flexi buffer, $1.0 \mu \mathrm{L}$ of $2 \mathrm{mM}$ deoxynucleotide triphosphates (DNTP), $7.5 \mu \mathrm{L}$ of $3.75 \mathrm{mM} \mathrm{MgCl}_{2}, 2 \mu \mathrm{L}$ of $10 \mathrm{pM}$ stock of each primer, $2.5 \mu \mathrm{L}$ of Thermus aquaticus (Taq) polymerase from PCR core kit (Promega Madison, WI). Three microliters of template DNA was pipetted into $0.5 \mathrm{~mL}$ thin - walled PCR tube followed by the addition of $47 \mu \mathrm{L}$ of the master mix, to total $50 \mu \mathrm{L}$ for the final volume in each tube. The reaction tube was pulse centrifuged for $5 \mathrm{~s}$. PCR cycling parameters were as follows: for the $16 \mathrm{~S}$ rRNA gene $94^{\circ} \mathrm{C}$ for $10 \mathrm{~min}$ (initial denaturation), $94^{\circ} \mathrm{C}$ for $1 \mathrm{~min}$ (denaturation), $68^{\circ} \mathrm{C}$ for $25 \mathrm{sec}$ (annealing), and $72^{\circ} \mathrm{C}$ for $30 \mathrm{sec}$ (extension). There were $30 \mathrm{cycles}$ in steps 2 through 4 and final extension at $72^{\circ} \mathrm{C}$ for $10 \mathrm{~min}$. For the yst gene initial denaturation at $94^{\circ} \mathrm{C}$ for 2 $\min , 92^{\circ} \mathrm{C}$ at $30 \mathrm{sec}$ (denaturation), $59^{\circ} \mathrm{C}$ for $30 \mathrm{sec}$ (annealing), and $72^{\circ} \mathrm{C}$ at 30 sec (extension). There were 40 cycles in steps 2 through 4 with the final extension at $72^{\circ} \mathrm{C}$ for $5 \mathrm{~min}$. For the inv gene initial denaturation was $95^{\circ} \mathrm{C}$ for $1 \mathrm{~min}$, $94^{\circ} \mathrm{C}$ at $15 \mathrm{sec}$ (denaturation), $72^{\circ} \mathrm{C}$ for $30 \mathrm{sec}$ (annealing), and $72^{\circ} \mathrm{C}$ for $30 \mathrm{sec}$ (extension). There were 40 cycles in steps 2 through 4 with the final extension for $72^{\circ} \mathrm{C}$ at $10 \mathrm{~min}$. For the ail gene initial denaturation at $94^{\circ} \mathrm{C}$ for $1 \mathrm{~min}, 94^{\circ} \mathrm{C}$ for $30 \mathrm{sec}$ (denaturation), $55^{\circ} \mathrm{C}$ for $1 \mathrm{~min}$ (annealing), and $70^{\circ} \mathrm{C}$ for $2 \mathrm{~min}$

Table 2. Presumptive positives for Yersinia on MAC and CIN agar, and 16S rRNA positive.

\begin{tabular}{cccc}
\hline Sample Type & MAC & CIN & 16S rRNA \\
\hline Milk & 28 & 21 & $3(2.6 \%)$ \\
Fecal & 45 & 33 & $2(1.7 \%)$ \\
Chitterlings & 27 & 20 & $8(6.9 \%)$
\end{tabular}


(extension). There were 25 cycles in steps 2 through 4 with a final extension of $70^{\circ} \mathrm{C}$ for $5 \mathrm{~min}$. For the vir $\mathrm{F}$ gene initial denaturation was $94^{\circ} \mathrm{C}$ for $1 \mathrm{~min}, 94^{\circ} \mathrm{C}$ for $45 \mathrm{sec}$ (denaturation), $57^{\circ} \mathrm{C}$ for $45 \mathrm{sec}$ (annealing), and $72^{\circ} \mathrm{C}$ for $45 \mathrm{sec}$ (extension). There were 30 cycles in steps 2 through 4 with a final extension of $72^{\circ} \mathrm{C}$ for 4 min.

For the yst $\mathrm{B}$ gene initial denaturation was $95^{\circ} \mathrm{C}$ for $5 \mathrm{~min}, 95^{\circ} \mathrm{C}$ for $40 \mathrm{sec}$ (denaturation), $58^{\circ} \mathrm{C}$ for $40 \mathrm{sec}$ (annealing), and $72^{\circ} \mathrm{C}$ for $60 \mathrm{sec}$ (extension). There were 30 cycles in steps 2 through 4 with a final extension of $72^{\circ} \mathrm{C}$ for 8 min. For the yadA gene, initial denaturation was $94^{\circ} \mathrm{C}$ for $5 \mathrm{~min}, 94^{\circ} \mathrm{C}$ for $15 \mathrm{sec}$ (denaturation), $60^{\circ} \mathrm{C}$ for $30 \mathrm{sec}$ (annealing), and $72^{\circ} \mathrm{C}$ for $30 \mathrm{sec}$ (extension). There were 25 cycles in steps 2 through 4 with a final extension at $72^{\circ} \mathrm{C}$ for 10 min. For the $r f b \mathrm{C}$ gene, initial denaturation was $95^{\circ} \mathrm{C}$ for $10 \mathrm{~min}, 95^{\circ} \mathrm{C}$ for $30 \mathrm{sec}$ (denaturation), $55^{\circ} \mathrm{C}$ for $1 \mathrm{~min}$ (annealing), and $72^{\circ} \mathrm{C}$ for $1 \mathrm{~min}$ (extension). There were 30 cycles in steps 2 through 4 with a final extension at $72^{\circ} \mathrm{C}$ for 10 min. For the yst $\mathrm{C}$ gene, initial denaturation was $94^{\circ} \mathrm{C}$ for $10 \mathrm{~min}, 94^{\circ} \mathrm{C}$ for $60 \mathrm{sec}$ (denaturation), $38^{\circ} \mathrm{C}$ for $60 \mathrm{sec}$ (annealing), and $72^{\circ} \mathrm{C}$ for $60 \mathrm{sec}$ (extension). There were 30 cycles in steps 2 through 4 with a final extension of ${ }^{\circ} \mathrm{C}$ for $10 \mathrm{~min}$. Positive and negative controls were included in all the PCR reactions.

The agarose gels went through gel electrophoresis on a voltage range of 68 75, and for 45 - 60 minutes. Gels were stained in ethidium bromide for one hour. Images from the gels were analyzed with Foto/analyst Luminary FX, an Electrophoresis Documentation and Analysis System (Fotodyne Inc., Rochester, NY).

\subsection{Antimicrobial Susceptibility Testing Using the Disc Diffusion Method}

Bacterial isolates were grown in Mueller-Hinton broth (MHB) for $24 \mathrm{~h}$ and swabbed evenly onto the surface of Mueller-Hinton agar (MHA) using sterile cotton swabs. The bacterium concentration was determined according to the 0.5 McFarland standard. The isolates were spiral-plated onto MHA and allow drying for 30 minutes. The following antimicrobial drugs and doses were used to test for drug resistance: ampicillin (AMP) $10 \mu \mathrm{g}$, amoxicillin-clavulanic acid (AMC) $30 \mu \mathrm{g}$, ciprofloxacin (CIP) $5 \mu \mathrm{g}$, kanamycin (KAN) $30 \mu \mathrm{g}$, streptomycin (S) 10 $\mu \mathrm{g}$, tetracycline (TE) $30 \mu \mathrm{g}$, trimethoprim (W) $5 \mu \mathrm{g}$, cefotaxime (CTX) $30 \mu \mathrm{g}$, and gentamicin (GN) $10 \mu \mathrm{g}$.

Antibiotic impregnated filter paper discs (Difco) at different concentrations were placed on the surface of each plate for each isolate, for a total of 9 discs using a Dispens-O-Disc dispenser (Difco) and incubated at $37^{\circ} \mathrm{C}$ for $16-18 \mathrm{~h}$. Inhibition zones were measured to the nearest millimeter [23]. Inhibition zones were indicated by a lack of microbial growth due to inhibitory concentrations of antibiotic diffused into semisolid culture media (agar) beneath the antibiotic-impregnated disc. Characterizations of strains based on the size of the inhibition zones around each disc were determined by measuring to the nearest millimeter $(\mathrm{mm})$. The zones of inhibitions (ZOI) were compared to control isolates through this study. 


\subsection{Enterobacterial Repetitive Intergenic Consensus (ERIC)-PCR}

DNA extractions were performed by the following way: the master mix contained $2 \mu \mathrm{L}$ of DNA template, $8.2 \mu \mathrm{L}$ of $\mathrm{dH}_{2} \mathrm{O}, 10 \mu \mathrm{L}$ of Syber Green, and $0.8 \mu \mathrm{L}$ of primer Eric2 to total the volume to $20 \mu \mathrm{L}$. The primer used was ERIC2 (5'-AAGTAAGTGACTGGGGTGAGCG-3'). Real-time PCR was used and the conditions were as follows: initial denaturation of $7 \mathrm{~min}$ at $94^{\circ} \mathrm{C}, 94^{\circ} \mathrm{C}$ for $30 \mathrm{sec}$ (denaturation), $52^{\circ} \mathrm{C}$ for $1 \mathrm{~min}$ (annealing), and $65^{\circ} \mathrm{C}$ for $8 \mathrm{~min}$ (extension). There were 30 cycles during steps 2 through 4 , with a final extension of $65^{\circ} \mathrm{C}$ at $10 \mathrm{~min}$. This process was completed twice [24]. The 1.6\% agarose gels went through gel electrophoresis for $1-1.5$ hours and stained in ethidium bromide. Images from the gels were analyzed with Foto/analyst Luminary FX, an Electrophoresis Documentation and Analysis System (Fotodyne Inc.). The data were analyzed with the GelCompar 2.0 for Windows program. The distance between clusters and similarity were calculated using the unweighted pair group method with arithmetic averages (UPGMA). A cut-off $\geq 85 \%$ was used to determine groups that were identified as genetically related.

\subsection{Random Amplified Polymorphic DNA}

A combination of $15 \mu \mathrm{L}$ of sterile, distilled water; $5 \mu \mathrm{L}$ of primer; and $5 \mu \mathrm{L}$ of DNA were prepared in a sterile environment. A total of 4 primers were utilized from the Ready-To-Go RAPD Analysis beads kit (GE Healthcare Life Sciences). The thermo-cycler parameters were $95^{\circ} \mathrm{C}$ for one minute of denaturation, $36^{\circ} \mathrm{C}$ for one minute of annealing, and $72^{\circ} \mathrm{C}$ for two minutes of extension. There was a total of forty-five cycles. RAPD analysis beads were placed into each tube. A $1.6 \%$ agarose gel underwent gel electrophoresis at a voltage of 75 for one-half hours. The gel was stained in ethidium bromide for one hour, and viewed by UV trans illumination and photographed. The gels were stained with ethidium bromide and documented and analyzed with Foto/analyst Luminary FX, an Electrophoresis Documentation and Analysis System (Fotodyne Inc.) The distances between clusters were calculated using the unweighted pair group method with arithmetic averages (UPGMA). A cut-off $\geq 85 \%$ was used to determine groups that were identified as genetically related.

\subsection{Data Analysis}

Statistical analysis of the data pertaining to antimicrobial susceptibility was performed with SAS. A P value $<0.05$ was used to determine statistical significance.

\section{Results}

\subsection{Isolation of Samples}

From a total of 40 milk samples, $70 \%$ were presumptive positive for MacConkey agar while 52.5\% were presumptive positive for CIN agar Figure 1 and Figure 2. After isolation of the 45 fecal samples all samples were presumptive positive on MacConkey agar, yet $73 \%$ of the samples were presented on the CIN agar. The 


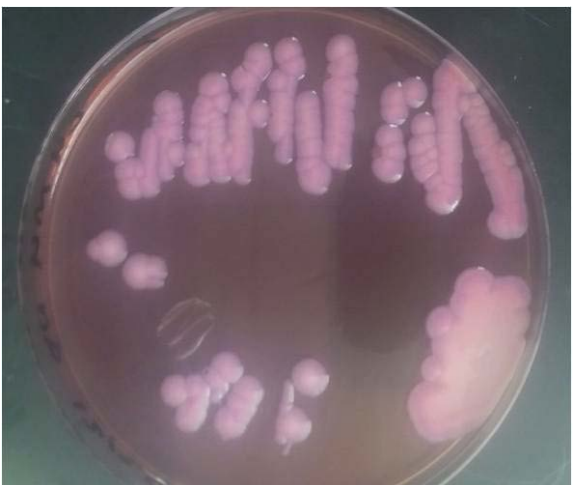

(a)

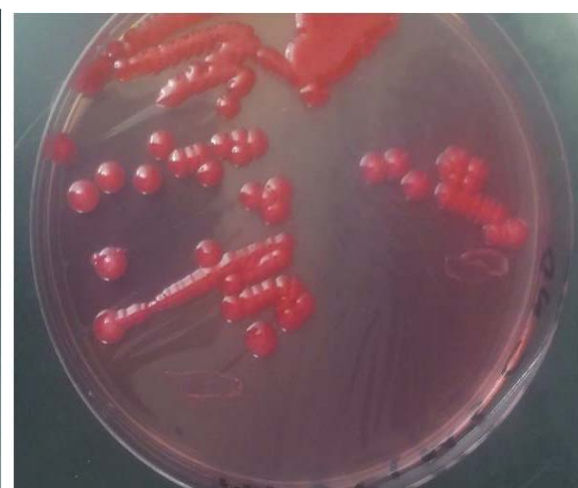

(b)

Figure 1. (a) Presumptive positive Yersinia colonies, pink colonies grown on CIN agar; (b) Presumptive positive Yersinia colonies, red colonies grown on CIN agar.
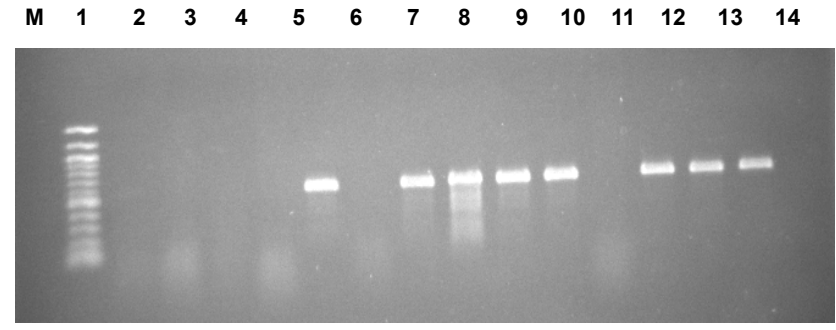

(a)

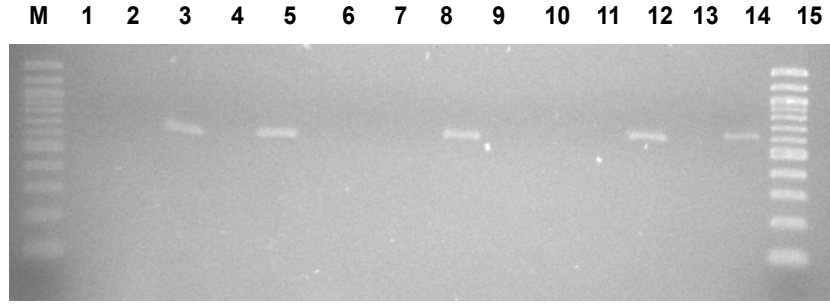

(b)

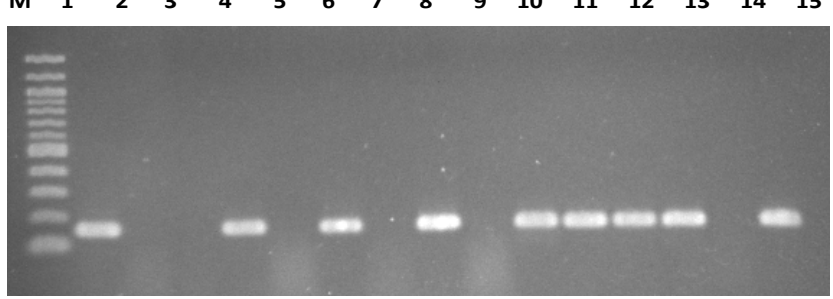

(c)

Figure 2. (a) Illustrates Yersinia isolates identified with various virulence genes; (b) Detection of $Y$. enterocolitica virulence gene (inv) by PCR. Lane M: 100 bp DNA Marker, 1-ATCC 9610, 2-ATCC 29743, 3-SM 157, 4-SM 160, 5-SC 47, 6-SF 80, 7-SC 33, 8-SM 19, 9-SC 49, 10-SC 57, 11-SF 6, 12-SC 43, 13-SC 59, 14-SC 37; (c) Detection of $Y$. enterocolitica virulence gene (virF) by PCR. Lane M: 100 bp DNA Marker, 1-ATCC 29743, 2-ATCC 9610, 3-SM 19, 4-SM 157, 5-SC 57, 6-SC 55, 7-SF 6, 8-SC 43, 9-SC 33, 10-SF 80, 11-SC 59, 12-SC 37, 13-SC 49, 14-SM 160, 15-SC 47, M: 100 bp DNA Marker.

chitterling samples revealed $90 \%$ to be presumptive positive for MacConkey agar, with $67 \%$ of the samples presumptive positive for CIN agar as described in Table 3. Colonies that were isolated from the samples are shown in Figure 3. CIN agar was the source of $84.6 \%$ of Yersinia isolates. Only two positive samples (15\%) were retrieved from the MAC agar.

\subsection{Polymerase Chain Reaction (PCR)}

$11.3 \%(13 / 115)$ of all samples contained the 16s rRNA gene, identifying them as Yersinia enterocolitica. Of the 105 presumptive positives, $12.4 \%$ (13/105) were $Y$. enterocolitica. From the milk samples, $7.5 \%$ presented the $16 \mathrm{~S}$ rRNA gene. 
Table 3. Drug resistance and virulence genes present in $Y$. enterocolitica samples.

\begin{tabular}{|c|c|c|c|}
\hline Strain $^{1}$ & Source & Drug Resistance ${ }^{2}$ & Virulence Genes \\
\hline SM-19 & Milk & AMC, S, AMP & $y s t$, inv, ail, vir $\mathrm{F}, \operatorname{yad} \mathrm{A}, r f b \mathrm{C}$ \\
\hline SM-157 & Milk & AMC, S, AMP & - \\
\hline SM-160 & Milk & AMC, AMP & - \\
\hline SC-33 & Chitterlings & AMP & yst, inv, ail, virF, $r f b \mathrm{C}$ \\
\hline SC 37 & Chitterlings & S, AMP, TE & $y s t$, inv, ail, rfbC \\
\hline SC 43 & Chitterlings & S, AMP & $y s t$, inv, ail, $r f b C$ \\
\hline SC 47 & Chitterlings & S, AMP & yst, inv, ail, virF, $r f b \mathrm{C}$ \\
\hline SC 49 & Chitterlings & AMC, S, AMP & $y s t$, inv, ail, virF, $r f b \mathrm{C}$ \\
\hline SC 55 & Chitterlings & AMC, AMP & yadA \\
\hline SC 57 & Chitterlings & S, AMP, TE & yst, inv, ail, virF, $r f b \mathrm{C}$ \\
\hline SC 59 & Chitterlings & S, AMP, TE & $y s t$, inv, ail, $r f b C$ \\
\hline SF 6 & Fecal & $\mathrm{TE}$ & - \\
\hline SF 80 & Fecal & TE & - \\
\hline$Y$. enterocolitica & ATCC 9610 & - & Yst \\
\hline Y. ruckeri & ATCC 29743 & $\begin{array}{c}\text { AMC, CIP, S, AMP, } \\
\text { TE, W, CTX }\end{array}$ & N/A \\
\hline
\end{tabular}

${ }^{1}$ SM: Milk, SC: Chitterlings, SF: Fecal; ${ }^{2}$ Abbreviations: AMC: Amoxicillin-Clavulanic Acid, CIP: Ciprofloxacin, K: Kanamycin, S: Streptomycin, AMP: Ampicillin, TE: Tetracycline, W: Trimethoprim, CTX: Cefotaxime and GN: Gentamycin.

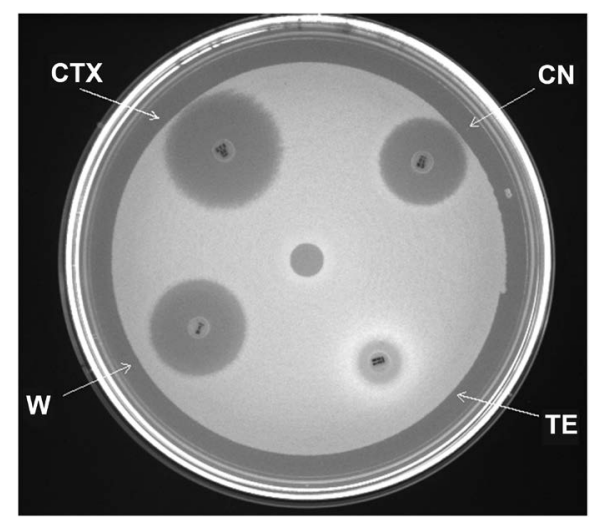

(a)

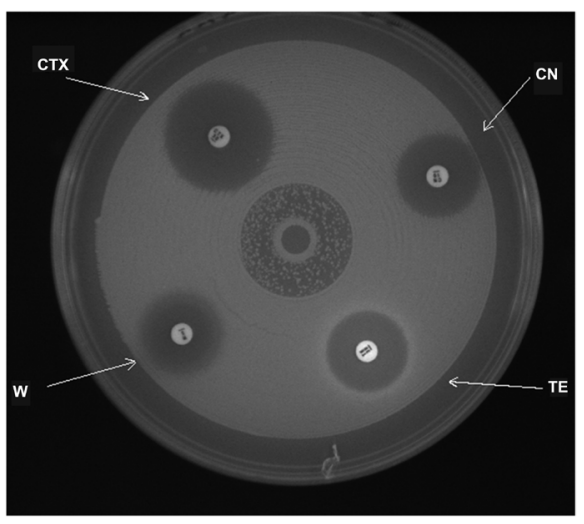

(b)

Figure 3. (a) Disc diffusion with Mueller-Hinton agar after isolation from milk source; (b) Disc diffusion with Mueller-Hinton agar after isolation from chitterlings source.

When compared to all 115 samples, $2.6 \%$ of $Y$. enterocolitica isolates were derived from the milk. Additionally, $4.4 \%$ of the fecal samples were identified with the $16 \mathrm{~S}$ rRNA gene. When the fecal was compared to all samples, $1.7 \%$ of $Y$. enterocolitica samples came from fecal. Lastly, $26 \%$ of the chitterling samples revealed the $16 \mathrm{~S}$ rRNA gene as defined in Table 3. In contrast to all samples, $7 \%$ of chitterling samples contained the $16 \mathrm{~S}$ rRNA gene. 
After evaluating the 13 confirmed $Y$. enterocolitica samples for traits of pathogenicity, $61.5 \%(8 / 13)$ of the Yersinia isolates carried the $y s t$, inv, ail, and $r f b c$ gene. 38.5\% (5/13) samples carried the virF gene; in conjunction with the $y s t$, inv, ail, and $r f b c$ genes. $15 \%$ (2/13) carried the yadA gene, while 7.7\% (1/13) isolates carried the yadA in combination with the $y s t$, inv, ail, and $r f b c$ genes. $69.2 \%$ (9/13) of the Yersinia isolates were pathogenic, while 30.8\% (4/13) were non-pathogenic. As shown in Table 3, 1 milk sample was virulent (7.7\%), 7 chitterling samples were virulent (53.8\%), and the fecal samples were shown to be non-pathogenic.

\subsection{Disc Diffusion}

All 13 Yersinia isolates were susceptible to ciprofloxacin, kanamycin, trimethoprim, cefotaxime, and gentamycin. Therefore, $55.5 \%$ of the antimicrobial agents were effective against the samples. Resistance to amoxicillin-clavulanic acid was found in $38.5 \%$ of samples, $53.8 \%$ were susceptible, and $7.7 \%$ were suggested to be intermediate. Streptomycin was ineffective to over half of the samples, with $61.5 \%$ being resistant. $30.8 \%$ of isolates demonstrated susceptibility, and $7.7 \%$ were intermediate. Ampicillin appeared to present the least amount of influence, with $84.6 \%$ of the samples being resistant to the antibiotic. While only $15 \%$ of samples were susceptible to ampicillin, there were no intermediate findings. Results were roughly equal with Tetracycline; where $38.5 \%$ of isolates were resistant, $30.8 \%$ showed susceptibility, and $30.8 \%$ left intermediate effects.

Table 3 is a representation of all antibiotics that resulted in drug resistance to the various sample isolates. Figure 3(a) and Figure 3(b) represents antimicrobial testing and zones of inhibition from milk and chitterling samples due to testing with the various antimicrobials. Figure 4 is a summary of the influences of each antimicrobial drug. The positive control ATCC 9610 displayed a trend of being susceptible to all antibiotics that were tested. The negative control ATCC 29743 left an oppositional impact, where it was resistant to all except two of the antimicrobial agents. Treatment with gentamycin resulted in susceptibility, while the negative control was intermediate to kanamycin.

\subsection{ERIC-PCR}

There was $75 \%$ similarity among the two fecal isolates, one milk isolate, one chitterling isolate, and control Yersinia ruckeri (SF-80, SM-160, SF-6, SC-55, ATCC 29743). SF-6 and SM-160 presented a similarity of 90\%. There was approximately an $85 \%$ similarity between the remaining two $Y$. enterocolitica milk isolates, 6 chitterling isolates, and control ATCC 9610 Y. enterocolitica. There was a $95 \%$ similarity between SM-19 and SC-49, which was the largest similarity among all samples. When comparing the two major clusters, there was an overall similarity of $65 \%$. The final chitterling isolate (SC-59) showed the least amount of similarity of $50 \%$ when compared to all the other samples. ATCC 9610 and SC-47 had a similarity of $90 \%$. 


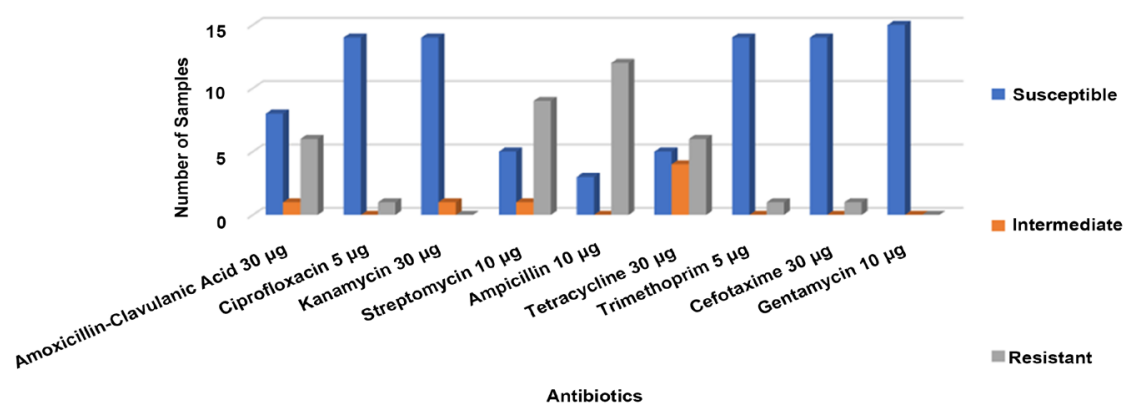

Figure 4. Graph illustrating Yersinia isolates responses to antimicrobial testing.

\subsection{Random Amplified Polymorphic DNA}

Primer 3 presented $30 \%$ similarity between a chitterling and milk sample. There was $40 \%$ similarity among one chitterling and one fecal sample. When ATCC $9610 Y$. enterocolitica was compared to four chitterlings and one milk sample $30 \%$ similarity was found. There was one chitterling sample that had no similarity with any of the other samples that were tested. The two major clusters had an overall similarity of $5 \%$. There were two chitterling samples that were $65 \%$ similar, as well as one milk and one chitterling. Primer 4 showed higher rates of similarity, which consisted of a chitterling and milk sample with $97 \%$ similarity. Two other chitterlings and milk sample had similarity at 95\%. When comparing the two fecal isolates with two chitterlings and two milks, there was $60 \%$ similarity. Two other chitterlings were $85 \%$ similar and two different chitterling samples were $90 \%$ similar.

Primer 5 showed a $75 \%$ similarity between a fecal and chitterling sample. $65 \%$ similarity was seen in the two fecal samples with a chitterling sample. There was $85 \%$ similarity between a milk and chitterlings samples. Six chitterlings were $80 \%$ similar with a milk sample. When all samples were compared, there was 35\% similarity. Primer 6 had 90\% similarity in two chitterling samples. 97\% similarity was seen in two milk samples, and 85\% between ATCC 9610 and a chitterling. There was approximately $85 \%$ similarity between two chitterlings and one fecal sample.

\section{Discussion}

$Y$. enterocolitica infection is a wide spread cause of foodborne illness, with signs of infection being fever, diarrhea, nausea, stomach pain, and gastroenteritis [18]. The primary reservoir for pathogenic forms of $Y$. enterocolitica is pigs, although they do not present any physical symptoms [25]. Outcomes of this study demonstrated that chitterling source had the highest rate of virulent genes, totaling $53.8 \%$. There is a risk of contamination with pathogenic $Y$. enterocolitica transferred from the intestinal contents of pigs [26]. With the currence of somewhat 
higher incidence during winter among black children younger than 5 years old, it is suggested that chitterlings might still be a cause of infection [7].

Neither of the Yersinia isolates from swine fecal in the current study were identified as pathogenic. The majority (85\%) of rectal swabs evaluated were non-pathogenic and grouped as biotype 1A. Similarly, ITC broth (warm culture) was used to isolate the strains from wild boar, with a larger rate of isolation obtained from PSBB (cold culture) [27]. Cold enrichment was most effective for retrieving Yersinia enterocolitica. Pig tonsils are considered the best choice of tissue to identify the presence of pathogens. They tend to have greater amounts of contamination [28]. Samples from the present study were enriched with ITC broth at $25^{\circ} \mathrm{C}$ for 7 days then streaked onto agar plates to incubate at $30^{\circ} \mathrm{C}$ for 48 $\mathrm{h}$, and resulted in $11.3 \%$ of the isolates identified as part of the Yersinia species carrying the $16 \mathrm{~S}$ rRNA gene. Of these isolates, $23 \%$ came from cow milk, $15 \%$ from swine fecal, and $61.5 \%$ from chitterlings. While examining pig tonsils, samples were enriched and streaked under the same parameters. From the ITC enrichment, $38.4 \%$ Yersinia enterocolitica isolates were recovered. CIN and SSDC agar were used to obtain the colonies, but all the positives coming from CIN [29]. The present study used CIN and MCA agar, with $84.6 \%(11 / 13)$ of Yersinia isolates coming from CIN.

The raw cattle milk from the present study resulted in $7.7 \%$ being pathogenic in comparison to all samples. The isolate carried the following genes: yst, inv, ail, $v i r \mathrm{~F}, \operatorname{yadA}$, and $r f b \mathrm{C}$. When different types of raw milk sources were tested, the largest percentage of $Y$. enterocolitica was observed in $5.8 \%$ of cattle milk. A total of 240 cow milk samples were evaluated [30]. The present study was much smaller, while analyzing only 40 milk samples. A strain of $Y$. enterocolitica obtained from milk was shown to convey four virulence genes (inv, ail, yst $A$ and $v i r F$ ). Virulence was presented from all the phenotypic tests. It was concluded that this strain that was classified as biotype 2 had the possibility to cause disease [24].

The positive control ATCC 9610 did not show up in all the PCR virulence tests. It was not observed for ail, yadA, $r f b C$, virF, $y s t B$, inv, and $y s t C$. The only gene where the positive control was recognized was with $y s t$. Samples were identified with the appropriate gene by measuring the predetermined base pair length. The ail gene was not identified in the two biotype $1 \mathrm{~A}$ isolates evaluated, however; the gene was observed in all pathogenic biotypes $(1 \mathrm{~B}, 2,3,4)$ excluding the $1 \mathrm{~B} / \mathrm{O}: 8$ strain which was ATCC 9610 . The results found for uncovering the yadA gene in $Y$. enterocolitica was alike, where the gene was not noticed in two of the 1B strains [31]. There was no success in amplifying the reference strain ATCC 9610, which was obtained by ATCC in the year 1939. This may have been caused by absence of the virulence trait following several passages [32]. ATCC 9610 was determined to be avirulent [33]. Each sample was testing three times during disc diffusion. All samples including controls were susceptible to ciprofloxacin, kanamycin, trimethoprim, cefotaxime, and gentamycin. Similarly, when the MIC method was used to measure antimicrobial resistance in $Y$. enterocoli- 
tica isolates, no resistance was seen in ciprofloxacin, gentamycin, kanamycin, and cefotaxime [34].

Major errors occurred during disc diffusion on $Y$. enterococolitica isolates, suggesting that the results from that tool of research are not credible in determining the rate of resisting antimicrobials [35]. Slightly less than half of the antimicrobial drugs were resisted by $Y$. enterocolitica isolates during this experiment. In the present study, $61.5 \%$ of the samples were resistant to streptomycin, $84.6 \%$ to ampicillin, and $38.5 \%$ to tetracycline. This compares to $11.9 \%$ of $Y$. enterocolitica O:3 strains that were resistant to streptomycin, $6.8 \%$ of multiresistance samples that including ampicillin and streptomycin, and tetracycline being susceptible [34]. $Y$. enterocolitica isolates tested $100 \%$ resistant to ampicillin. A total of $8 \%$ were resistant to trimethoprim, and $12 \%$ resisted tetracycline [36]. From the 115 samples, Yersinia was detected at a rate of $11.3 \%$ in the current study. FoodNet 2016, preliminary data reported a steady increase in Yersinia diagnoses. It was suggested that the bacterium was under detected prior to changes recently made in testing procedures. In 2016 Yersinia infection reports were measured at $32 \%$, with a total of 302 confirmed infections [37].

From this study, the chitterling samples showed the most genetic similarity, as bands from the ERIC-PCR gels had similar patterns. The virulent strains were similar at $85 \%$, as were the non-virulent strains at $80 \%$. It was observed that virulent Yersinia enterocolitica strains isolated from food sources presented more similarity at $70 \%$ than strains isolated from other types of food sources, which fell below 50\% (Falcao et al., 2006). From pork tonsil samples, a cluster pattern was not observed due to the $90 \%$ similarity cut-off point. Four different ERIC-PCR patterns were identified in $Y$. enterocolitica isolates [38]. From RAPD, there were multiple genetic similarities associated with each primer that was used. Nine of the 13 Yersinia isolates had similar profiles. However; all the bands did not show up on the gel. From the 16 serotype O:3 Y. enterocolitica strains that were isolated from pigs, 15 of them had a similar profile. There were bands seen on the gel that were not noticeable on the picture [39]. Although different primers were used, a large genetic diversity was found in the strains that were tested [40].

Further research is recommended on pork, particularly chitterling samples being enriched in PSBB at cold temperatures to compare the rate of isolation to the present study. Also, these samples should be collected from a recently slaughtered pig, instead of purchasing chitterlings from a store as freezing may have influenced the viability of the bacteria. Pig's milk should also be evaluated to clarify speculations of $Y$. enterocolitica being transferred to piglets during the nursing phase. It is recommended that piglet fecal also be tested for pathogens. The results from using ATCC 9610 were not as expected. It is recommended that a different positive control be used in future research.

\section{Conclusion}

In conclusion, foodborne illness is an issue that consumers continue to face. 
Young children and the elderly tend to be more impacted by sickness from $Y$. enterocolitica than other age groups. The results from this study suggest that the pathogen is present in uncleaned, uncooked chitterlings and raw dairy milk in the state of North Carolina. Genetic testing also suggests that some of the Yersinia isolates may be generated from an unidentified, common source. Precautions should be taken especially during the colder months of the year on farm animals, as well as hygiene of farmers to minimize the risk of spreading infection.

\section{Conflicts of Interest}

The authors declare no conflicts of interest regarding the publication of this paper.

\section{References}

[1] CDC (2016) Yersinia enterocolitica. http://www.cdc.gov/yersinia/index.html

[2] USDA (2011) Yersiniosis and Chitterlings: Tips to Protect You and Those You Care for from Foodborne Illness. http://permanent.access.gpo.gov/gpo19104/Yersiniosis-and-Chitterlings

[3] Valentin-Weigand, P., Heesemann, J. and Dersch, P. (2014) Unique Virulence Properties of Yersinia enterocolitica O:3-An Emerging Zoonotic Pathogen Using Pigs as Preferred Reservoir Host. International Journal of Medical Microbiology, 304, 824-834. https://doi.org/10.1016/j.ijmm.2014.07.008

[4] Rahman, A., Bonny, T., Stonsaovapak, S. and Ananchaipattana, C. (2011) Yersinia enterocolitica: Epidemiological Studies and Outbreaks. Journal of Pathogens, 2011, Article ID: 239391. https://doi.org/10.4061/2011/239391

[5] Linscott, A. (2011) Food-Borne Illnesses. Clinical Microbiology Newsletter, 33, 41-45. https://doi.org/10.1016/j.clinmicnews.2011.02.004

[6] Food Net (2016).

[7] Ong, K., Gould, L., Chen, D., Jones, T., Scheftel, J., Webb, T., Mody, R. and Mahon, B. (2012) Changing Epidemiology of Yersinia enterocolitica Infections: Markedly Decreased Rates in Young Black Children, Foodborne Diseases Active Surveillance Network (FoodNet). Clinical Infection Disease, 54, S385-S390. https://doi.org/10.1093/cid/cis053

[8] MacDonald, E., Heier, B., Stalheim, T., Cudjoe, K., Skjerdal, T., Wester, A., Lindstedt, B. and Vold, L. (2011) Yersinia enterocolitica O:9 Infections Associated with Bagged Salad Mix in Norway, February to April 2011. Euro Surveill, 16, 1-3.

[9] Al-Kharousi, Z., Guizani, N., Al-Sadi, A., Al-Bulushi, I. and Shaharoona, B. (2016) Hiding in Fresh Fruits and Vegetables: Opportunistic Pathogens May Cross Geographical Barriers. International Journal of Microbiology, 2016, Article ID: 4292417. https://doi.org/10.1155/2016/4292417

[10] FDA (2015) Analysis and Evaluation of Preventive Control Measures for the Control and Reduction/Elimination of Microbial Hazards on Fresh and Fresh-Cut Produce: Chapter IV Outbreaks Associated with Fresh and Fresh-Cut Produce. Incidence, Growth, and Survival of Pathogens in Fresh and Fresh-Cut Produce.

[11] Wauters, G., Kandolo, K. and Janssens, M. (1987) Revised Biogrouping Scheme of Yersinia enterocolitica. Contributions to Microbiology and Immunology, 9, 14-21.

[12] Fredriksson-Ahomaa, M., Stolle, A. and Korkeala, H. (2006) Molecular Epidemiology of Yersinia enterocolitica Infections. FEMS Immunology and Medical Microbi- 
ology, 47, 315-329. https://doi.org/10.1111/j.1574-695X.2006.00095.x

[13] Bottone, E. (1999) Yersinia enterocolitica: Overview and Epidemiologic Correlates. Microbes and Infection, 1, 323-333. https://doi.org/10.1016/S1286-4579(99)80028-8

[14] Bacteriological Analytical Manual (2007).

[15] Gomez-Duarte, O., Bai, J. and Newel, E. (2009) Detection of E. coli, Salmonella spp., Shigella spp., Yersinia enterocolitica, Vibrio cholerae, and Campylobacter spp. Enteropathogens by Three-Reaction Multiplex PCR. Diagnostic Microbiology and Infectious Disease, 63, 1-9. https://doi.org/10.1016/j.diagmicrobio.2008.09.006

[16] Rasmussen, H.N., Rasmussen, O.F., Andersen, J.K. and Olsen, J.E. (1994) Specific Detection of Pathogenic Yersinia enterocolitica by Two-Step PCR Using Hot-Start and DMSO. Molecular and Cellular Probes, 8, 99-108. https://doi.org/10.1006/mcpr.1994.1014

[17] Nakajima, H., Inoue, M., Mori, T., Itoh, K., Arakawa, E. and Watanabe, H. (1992) Detection and Identification of Yersinia pseudotuberculosis and Pathogenic Yersinia enterocolitica by an Improved Polymerase Chain Reaction Method. Journal of Clinical Microbiology, 30, 2484-2486.

[18] Amin Askr, A.A.A.F., El Aal, S.F.A.A. and Amer, I.H. (2013) Prevalence of Virulent Yersinia enterocolitica in Subclinical Mastitic Cow Milk in Sharkia Governorate, Egypt. Life Science Journal, 10, 1285-1294.

[19] Garzetti, D., Susen, R., Fruth, A., Tietze, E., Heesemann, J. and Rakin, A. (2014) A Molecular Scheme for Yersinia enterocolitica Patho-Serotyping Derived from Genome-Wide Analysis. International Journal of Medical Microbiology, 304, 275-283. https://doi.org/10.1016/j.ijmm.2013.10.007

[20] Wang, X., Qiu, H., Jin, D., Cui, Z., Kan, B., Xiao, Y., Xu, Y., Xia, S., Wang, H., Yang, J., Wang, X., Hu, W., Xu, J. and Jing, H. (2008) O:8 Serotype Yersinia enterocolitica Strains in China. International Journal of Food Microbiology, 125, 259-266. https://doi.org/10.1016/j.ijfoodmicro.2008.04.016

[21] Weynants, V., Jadot, V., Denoel, P.A., Tibor, A. and Letesson, J. (1996) Detection of Yersinia enterocolitica Serogroup O:3 by a PCR Method. Journal of Clinical Microbiology, 34, 1224-1227.

[22] Bhagat, N. and Virdi, J.S. (2007) Distribution of Virulence-Associated Genes in Yersinia enterocolitica biovar 1A Correlates with Clonal Groups and Not the Source of Isolation. FEMS Microbiology Letters, 266, 177-183. https://doi.org/10.1111/j.1574-6968.2006.00524.x

[23] Clinical and Laboratory Standards Institute (2015) Performance Standards for Antimicrobial Susceptibility. Twenty-Fifth Informational Supplement. CLSI Document M100-S25.

[24] Falcao, J., Falcao, D.P., Pitondo-Silva, A., Malaspina, A.C. and Brocchi, M. (2006) Molecular Typing and Virulence Markers of Yersinia enterocolitica Strains from Human, Animal and Food Origins Isolated between 1968 and 2000 in Brazil. Journal of Medical Microbiology, 2006, 1539-1548.

https://doi.org/10.1099/jmm.0.46733-0

[25] Denis, M., Fondrevez, M., Labbe, A. and Houdayer, C. (2011) Genetic Characterization of Yersinia enterocolitica Collected from Tonsils of Slaughtered Pigs. Safe Pork, 2011, 53-56.

[26] Fondrevez, M., Minivell, B., Labbe, A., Houdayer, C., Rose, N., Esnault, E. and Denis, M. (2014) Prevalence of Pathogenic Yersinia enterocolitica in Slaughter-Aged Pigs during a One-Year Survey, 2010-2011, France. International Journal of Food Microbiology, 174, 56-62. https://doi.org/10.1016/j.ijfoodmicro.2013.12.027 
[27] Bancerz-Kisiel, A., Platt-Samoraj, A., Szczerba-Turek, A., Syczylo, K. and Szweda, W. (2015) The First Pathogenic Yersinia enterocolitica Bioserotype 4/O:3 Strain Isolated from a Hunted Wild Boar (Sus scrofa) in Poland. Epidemiology and Infection, 143, 2758-2765. https://doi.org/10.1017/S0950268814003872

[28] Van Damme, I., Berkvens, D., Botteldoorn, N., Dierick, K., Wits, J., Pochet, B. and De Zutter, L. (2013) Evaluation of the ISO 10273:2003 Method for the Isolation of Human Pathogenic Yersinia enterocolitica from Pig Carcasses and Minced Meat. Journal of Food Microbiology, 36, 170-175. https://doi.org/10.1016/j.fm.2013.05.007

[29] Bonardi, S., Alpigiani, I., Pongolini, S., Morganti, M., Tagliabue, S., Bacci, C. and Brindani, F. (2014) Detection, Enumeration and Characterization of Yersinia enterocolitica 4/O:3 in Pig Tonsils at Slaughter in Northern Italy. International Journal of Food Microbiology, 177, 9-15. https://doi.org/10.1016/j.ijfoodmicro.2014.02.005

[30] Jamali, H., Paydar, M., Radmehr, B. and Ismail, S. (2015) Prevalence, Characterization, and Antimicrobial Resistance of Yersinia enterocolitica Isolated from Raw Milk in Farm Bulk Tanks. Journal of Dairy Science, 98, 798-803. https://doi.org/10.3168/jds.2014-8853

[31] Cheyne, B.M., Van Dyke, M.I., Anderson, W.B. and Huck, P.M. (2010) The Detection of Yersinia enterocolitica in Surface Water by Quantitative PCR Amplification of the ail and yadA Genes. Journal of Water and Health, 8, 487-499.

https://doi.org/10.2166/wh.2009.215

[32] Uyeda, J., Harmon, K. and Wesley, I. (1997) A PCR Elisa Method for the Detection of Yersinia enterocolitica. Swine Research Report, 1996, 1-7.

[33] Thoerner, P., Bin Kingombe, C.I., Bogli-Stuber, K., Bissig-Choisat, B., Wassenaar, T.M., Frey, J. and Jemmi, T. (2003) PCR Detection of Virulence Genes in Yersinia enterocolitica and Yersinia pseudotuberculosis and Investigation of Virulence Gene Distribution. Applied and Environmental Microbiology, 69, 1810-1816. https://doi.org/10.1128/AEM.69.3.1810-1816.2003

[34] Von Altrock, A., Roesler, U., Merle, R. and Waldmann, K.H. (2010) Prevalence of Pathogenic Yersinia enterocolitica Strains on Liver Surfaces of Pigs and Their Antimicrobial Susceptibility. Journal of Food Protection, 73, 1680-1683. https://doi.org/10.4315/0362-028X-73.9.1680

[35] Meyer, C., Stolle, A. and Fredriksson-Ahomaa, M. (2011) Comparison of Broth Microdilution and Disk Diffusion Test for Antimicrobial Resistance Testing in Yersinia enterocolitica 4/O:3 Strains. Microbial Drug Resistance, 17, 479-484.

https://doi.org/10.1089/mdr.2011.0012

[36] Rusak, L.A., Falavina dos Reis, C.M., Barbosa, A.V., Merces Santos, A.F., Paixao, R., Hofer, E., Vallim, D.C. and Asensi, M.D. (2014) Phenotypic and Genotypic Analysis of Bio-Serotypes of Yersinia enterocolitica from Various Sources in Brazil. Journal of Infection in Developing Countries, 8, 1533-1540. https://doi.org/10.3855/jidc.4553

[37] Marder, E.P., Cieslak, P.R., Cronquist, A.B., Dunn, J., Lathrop, S., Rabatsky-Ehr, T., Ryan, P., Smith, K., Tobin-D’Angelo, M., Vugia, D.J., Zansky, S., Holt, K.G., Wolpert, B.J., Lynch, M., Tauxe, R. and Geissler, A.L. (2017) Incidence and Trends of Infections with Pathogens Transmitted Commonly through Food and the Effect of Increasing Use of Culture-Independent Diagnostic Tests on Surveillance-Foodborne Diseases Active Surveillance Network, 10 U.S. Sites, 2013-2016. Morbidity and Mortality Weekly Report, 66, 397-403. https://doi.org/10.15585/mmwr.mm6615a1

[38] Paixao, R., Moreno, L.Z., Sena de Gobbi, D.D., Raimundo, D.C., Ferreira, T.S.P., Spindola, M.G., Hofer, E., Falavina dos Reis, C.M., Matte, M.H. and Moreno, A.M. 
(2013) Genotypic Characterization of Yersinia enterocolitica Biotype 4/O:3 Isolates from Pigs and Slaughterhouses Using SE-AFLP, ERIC-PCR, and PFGE. Journal of Pathogens, 2013, Article ID: 521510. https://doi.org/10.1155/2013/521510

[39] Leal, T.C.A., Leal, N.C. and Paiva de Almedia, A.M. (1999) RAPD-PCR Typing of Yersinia enterocolitica (Enterobacteriaceae O:3 Serotype Strains Isolated from Pigs and Humans. Genetics and Molecular Biology, 22, 315-319. https://doi.org/10.1590/S1415-47571999000300005

[40] Shanmugapriya, S., Senthilmurugan, T. and Thayumanavan, T. (2014) Genetic Diversity among Yersinia enterocolitica Isolated from Chicken and Fish in and around Coimbatore City, India. Iranian Journal of Public Health, 43, 835-844. 